\title{
Phosphoproteomic Analysis of Gossypol-Induced Apoptosis in Ovarian Cancer Cell Line, HOCla
}

\author{
Lixu Jin, ${ }^{1}$ Yuling Chen, ${ }^{2}$ Xinlin Mu, ${ }^{3}$ Qingquan Lian, ${ }^{4,5}$ Haiyun Deng, ${ }^{4,5}$ and Renshan Ge $e^{4,5}$ \\ ${ }^{1}$ The First Affiliated Hospital of Wenzhou Medical University, Wenzhou, Zhejiang 325000, China \\ ${ }^{2}$ School of Life Sciences, Tsinghua University, Beijing 100084, China \\ ${ }^{3}$ Peking University People's Hospital, Beijing 100044, China \\ ${ }^{4}$ The Second Affiliated Hospital of Wenzhou Medical University, Wenzhou, Zhejiang 325027, China \\ ${ }^{5}$ Institute of Reproductive Biomedicine, Wenzhou Medical University, Wenzhou, Zhejiang 325027, China
}

Correspondence should be addressed to Haiyun Deng; hdeng8798@gmail.com and Renshan Ge; renshan_ge@163.com

Received 18 May 2014; Revised 18 July 2014; Accepted 20 July 2014; Published 12 August 2014

Academic Editor: Haiteng Deng

Copyright (C) 2014 Lixu Jin et al. This is an open access article distributed under the Creative Commons Attribution License, which permits unrestricted use, distribution, and reproduction in any medium, provided the original work is properly cited.

\begin{abstract}
Ovarian cancer is a major cause for death of gynecological cancer patients. The efficacy of traditional surgery and chemotherapy is rather compromised and platinum-resistant cancer recurs. Finding new therapeutic targets is urgently needed to increase the survival rate and to improve life quality of patients with ovarian cancer. In the present work, phosphoproteomic analysis was carried out on untreated and gossypol-treated ovarian cancer cell line, HOCla. We identified approximately 9750 phosphopeptides from 3030 phosphoproteins, which are involved in diverse cellular processes including cytoskeletal organization, RNA and nucleotide binding, and cell cycle regulation. Upon gossypol treatment, changes in phosphorylation of twenty-nine proteins including YAP1 and AKAP12 were characterized. Western blotting and qPCR analysis were used to determine expression levels of proteins in YAP1related Hippo pathway showing that gossypol induced upregulation of LATS1, which phosphorylates YAP1 at Ser 61. Furthermore, our data showed that gossypol targets the actin cytoskeletal organization through mediating phosphorylation states of actin-binding proteins. Taken together, our data provide valuable information to understand effects of gossypol on protein phosphorylation and apoptosis of ovarian cancer cells.
\end{abstract}

\section{Introduction}

Ovarian cancer is a major cause for death of gynecological cancer patients. Early diagnosis of ovarian cancer is difficult, while its progression is fast. The standard treatment is surgical removal followed by platinum-taxane chemotherapy. However, the efficacy of traditional surgery and chemotherapy is rather compromised and platinum-resistant cancer recurs in approximately $25 \%$ of patients within six months, resulting in $31 \%$ overall five-year survival rate [1-3]. Virtually no efficient second-line treatment is available. Therefore, a deep understanding of biology of ovarian cancer and finding new therapeutic targets are urgently needed to increase the survival rate and to improve life quality of patients with ovarian cancer.

Genomic analysis has shown that ovarian cancer is characterized by TP53 mutations in almost all tumors and by germline mutations in BRCA $1 / 2$ in approximately $10 \%$ of high-grade serous ovarian adenocarcinoma (HGS-OvCa) [4]. The Bcl-2 is a $26 \mathrm{kDa}$ integral membrane oncoprotein localized in the inner mitochondrial and cell membrane. The major function of $\mathrm{Bcl}-2$ is to inhibit apoptosis by arresting cells in the G0/G1 phase of cell cycle. It has been reported that $\mathrm{Bcl}-2$ proteins are overexpressed in many different solid tumors such as breast, prostate, and lung cancer and that serum Bcl-2 levels are also significantly higher in patients with ovarian cancer $[5,6]$. The structure of $\mathrm{Bcl}-2$ has $\mathrm{BH} 3$ domains, known as the $\mathrm{BH} 3$ binding groove, into which $\mathrm{Bad}$, $\mathrm{Bid}$, and Bim bind [7-9]. The binding groove in $\mathrm{Bcl}-2$ and Bcl-xL proteins is essential for their antiapoptotic function. The small molecules binding to the $\mathrm{BH} 3$ binding groove of $\mathrm{Bcl}-2 / \mathrm{Bcl}-\mathrm{xL}$ block the heterodimerization of $\mathrm{Bcl}-2$ with proapoptotic members of the Bcl-2 protein family, leading to apoptosis of cancer cells [10-12]. 
Gossypol is a phenolic aldehyde extracted from the cotton and the tropical plants. Gossypol forms an extensive hydrogen bonding network with residues Arg146 and Asn143 in Bcl-2 with the aldehyde group and the adjacent hydroxyl group on the right naphthalene ring [13]. Gossypol has been identified as a $\mathrm{BH} 3$-mimetic inhibitor of proapoptotic $\mathrm{Bcl}$ 2 family members, including $\mathrm{Bcl}-2, \mathrm{Bcl}-\mathrm{xL}$, and $\mathrm{Mcl}-1$, to induce apoptosis in cancer [14-17]. Gossypol is now in phase II and IIb clinical trials for hormone-refractory prostate cancer with promising initial results $[18,19]$. Gossypol and its derivatives have been found to act as an inhibitor for several dehydrogenase enzymes $[20,21]$ by binding to lactate dehydrogenase and inhibiting its activity. Gossypol also inhibits growth of prostate cancer cells by modulation of TGF beta/Akt signaling [22], activates p53 to induce apoptosis in prostate cancer cells [23], and enhances radiation-induced apoptosis through SAPK/JNK pathway [24]. On the other hand, gossypol and ApoG2 suppress the c-Myc signaling pathway [25] and NF-kappaB activity by decreasing NFkappaB-related gene expression in human leukemia U937 cells [26]. Furthermore, gossypol affects ROS-dependent mitochondria by activating death receptor 5 pathway in human colorectal carcinoma cells [27-29]. It also reversibly inhibits calcineurin and binds to calmodulin [30]. Recent studies have shown that gossypol and its enantiomer (AT101) regulate expressions of proangiogenic molecules released from cancer cells, suggesting the potential role of gossypol in antiangiogenesis by modulating VEGF signaling-mediated angiogenesis [31, 32]. Despite its involvement in signaling pathways, global phosphoproteomic analysis of gossypoltreated cancer cells has, however, not been performed that is important to identify the new gossypol-mediated cellular process and new therapeutic targets.

Protein phosphorylation is involved in diverse signaling pathways in cells and regulates a series of biological processes including cell growth, differentiation, proliferation, apoptosis, and even intercellular communication [33, 34]. Phosphorylation is the key process in tumor initiation and progression. Aberrant phosphorylation has been frequently linked to ovarian cancer. For example, activation of AKT2 kinase and PIK3CA has been found in ovarian cancer carcinogenesis [35-37]. EGFR has been found in 33-75\% of ovarian cancers and has been implicated for growth and progression of ovarian cancer. Signal transducer and activator of transcription 3 has been shown to be constitutively active in ovarian carcinoma cells and in drug-resistant ovarian cancer [38-41]. Proteomic methods have been developed over the last several years to characterize protein phosphorylation, including enrichment of low-abundance phosphoproteins or phosphopeptides with immobilized metal affinity chromatography (IMAC), strong cation exchange chromatography (SCX), or the two in combination $[42,43]$. Titanium dioxide $\left(\mathrm{TiO}_{2}\right)$ particles have been shown as an efficient affinity matrix to enrich phosphopeptides from a complex mixture [44].

In the present work, we have employed $\mathrm{TiO}_{2}$ particles as an affinity matrix to enrich phosphopeptides from ovarian cancer cell line, HOCla, which was developed in Beijing University Hospital. HOCla has been used as the model system to study the immunotherapy of ovarian cancers.
9750 phosphoproteins were identified in HOCla cells, and gossypol treatment resulted in changes in phosphorylation of 29 phosphoproteins including YAP1 and Ras GTPaseactivating protein-binding protein 1 . Our data indicate that gossypol modulates phosphorylation states of YAP1 and other actin-binding proteins that may affect cell migration and cell viability.

\section{Materials and Methods}

2.1. Chemicals and Reagents. Medium and serum were purchased from Wistent (Saint-Jean-Baptiste, CA) and used without further purification. Dithiothreitol (DTT) and iodoacetamide (IAA) were purchased from Sigma (St. Louis, MO). Sequence grade modified trypsin was purchased from Promega (Fitchburg, WI). $\mathrm{TiO}_{2}$ tips were from GL Sciences (Tokyo, Japan).

2.2. Cell Culture and Sample Preparation. The HOCla cell line was obtained from Peking University People's Hospital (Beijing, China). Cells were cultured in DMEM supplemented with $15 \%$ fetal bovine serum (FBS), 1\% penicillinstreptomycin (Wistent, Saint-Jean-Baptiste, CA) in $150 \mathrm{~mm}$ plates (Corning, New York, USA) and maintained at $37^{\circ} \mathrm{C}$ in a humidified atmosphere with $5 \% \mathrm{CO}_{2}$. Growth and morphology were continually monitored, and cells were passaged when they had reached $90 \%$ confluence. For gossypol treatment, $10 \mu \mathrm{M}$ gossypol dissolved in dimethyl sulfoxide (DMSO) was added into HOCla cells for a specific time. Cells were lysed in a buffer containing $1 \%$ Nonidet P-40, $0.1 \%$ sodium deoxycholate, $150 \mathrm{mM} \mathrm{NaCl}, 1 \mathrm{mM}$ EDTA, $50 \mathrm{mM}$ Tris, $\mathrm{pH} 7.5,1 \mathrm{mM}$ sodium orthovanadate, $5 \mathrm{mM}$ NaF, $5 \mathrm{mM}$ beta-glycerophosphate, and protease inhibitors (Complete Tablet, Roche Diagnostics). Lysates were centrifuged at $17,000 \times \mathrm{g}$ for $15 \mathrm{~min}$ to pellet cellular debris. The supernatant was collected.

\subsection{Analysis of Apoptosis by Propidium Iodide Staining.} Briefly, untreated and gossypol-treated HOCla cells were trypsinized, washed with ice-cold $0.9 \%$ PBS, and then fixed in precooled $70 \%$ ethanol at $4^{\circ} \mathrm{C}$ for $1.5 \mathrm{~h}$, respectively. After fixation, cells were washed with $0.9 \%$ PBS and resuspended in $0.5 \mathrm{~mL}$ PBS containing $250 \mu \mathrm{g} / \mathrm{mL}$ RNase A at $37^{\circ} \mathrm{C}$ for $30 \mathrm{~min}$. Cells were then incubated with $100 \mu \mathrm{g} / \mathrm{mL}$ propidium iodide (PI) in the dark at $4^{\circ} \mathrm{C}$ for $30 \mathrm{~min}$ before being transferred to FACS tubes for flow cytometry analysis. DNA content was analyzed using BD FACSCalibur (Becton Dickinson, Franklin Lakes, USA) and data were acquired and analyzed using CellQuest software (Becton Dickinson).

2.4. Enrichment of Phosphopeptides. Proteins were precipitated by addition of four volumes of methanol, one volume of chloroform, and three volumes of water in a sequential manner. The addition of each solvent was followed by a short vortex. After centrifugation at $17,000 \times \mathrm{g}$ for $1 \mathrm{~min}$, proteins were focused between organic and inorganic phases. The aqueous phase was discarded. Four starting volumes of methanol were then added to the protein pellet followed by a short vortex. After spinning down at $17,000 \times \mathrm{g}$ for $2 \mathrm{~min}$, 
methanol was removed, and the protein pellet was air-dried. Precipitated proteins were redissolved in a buffer containing $6 \mathrm{M}$ urea, $2 \mathrm{M}$ thiourea, and $50 \mathrm{mM}$ ammonium bicarbonate, $\mathrm{pH}$ 7.5. Protein concentrations were determined using a Bradford method. Equal amounts of proteins from untreated and gossypol-treated HOCla cells were used for phosphoproteomic analysis. Proteins were reduced with $1 \mathrm{mM}$ dithiothreitol for $1 \mathrm{~h}$ and alkylated with $5.5 \mathrm{mM}$ iodoacetamide for $45 \mathrm{~min}$ in the dark. After diluting for four times with $50 \mathrm{mM}$ ammonium bicarbonate, samples were digested overnight with sequencing grade modified trypsin $(1 / 50 \mathrm{w} / \mathrm{w})$. The digestion was quenched by adding trifluoroacetic acid. Peptides were desalted with Waters Oasis HLB 1cc column.

The digested peptides were mixed with $100 \mu \mathrm{L}$ binding buffer ( $0.3 \%$ TFA, $60 \%$ acetonitrile, and 25\% lactic acid) and loaded on $\mathrm{TiO}_{2}$ tip. After successive washing with washing buffer ( $0.4 \%$ TFA, $80 \%$ acetonitrile), an elution buffer containing 5\% ammonium hydroxide and 5\% pyrrolidine was used to elute phosphopeptides. Eluted peptides were acidified with TFA and desalted using C18 StageTips followed by LCMS/MS analysis.

\subsection{Characterization of Phosphorylation Sites of Proteins} in HOCla Cells. For LC-MS/MS analysis, phosphopeptides were separated by a 100 min gradient elution at a flow rate $0.250 \mu \mathrm{L} / \mathrm{min}$ with the EASY-nLCII integrated nano-HPLC system (Proxeon, Denmark) which was directly interfaced with a Thermo LTQ-Orbitrap mass spectrometer. The analytical column was a homemade fused silica capillary column (75 $\mu \mathrm{m}$ ID, 150 mm length; Upchurch, Oak Harbor, WA) packed with C-18 resin (300 A, $5 \mu \mathrm{m}$; Varian, Lexington, MA). Mobile phase A consisted of $0.1 \%$ formic acid, and mobile phase B consisted of $100 \%$ acetonitrile and $0.1 \%$ formic acid. An LTQ-Orbitrap mass spectrometer was operated in the data-dependent acquisition mode using Xcalibur 2.0.7 software and there is a single full-scan mass spectrum in the Orbitrap (400-1800 m/z, 30,000 resolution) followed by 20 data-dependent MS/MS scans in an ion trap at 35\% normalized collision energy (CID).

MS/MS spectra from each LC-MS/MS run were searched against the IPI human database using an in-house Mascot or Proteome Discoverer (Version 1.3) searching algorithm. The search criteria were as follows: full tryptic specificity was required; two missed cleavages were allowed; carbamidomethylation was set as fixed modification; oxidation (M) and phosphorylation (STY) were set as variable modifications; precursor ion mass tolerance was $10 \mathrm{ppm}$ for all MS acquired in the Orbitrap mass analyzer; and fragment ion mass tolerance was $0.5 \mathrm{Da}$ for all MS2 spectra acquired in the LTQ. High confidence score filter (FDR $<1 \%$ ) was used to select the "hit" peptides and their corresponding MS/MS spectra were manually inspected. Phosphorylation sites were determined by the PhosphoRS algorithm, which calculates the site probability to estimate that the site is truly phosphorylated. When the calculated $\mathrm{pRS}$ probability is above $75 \%$, the site assignment is considered to be the true hit. When a phosphopeptide was identified in more than three different experiments, label-free quantitation was carried out to determine its relative changes before and after gossypol treatment using the extracted ion current.

2.6. Western Blotting. $\mathrm{HOCla}$ cells were treated with $10 \mu \mathrm{M}$ gossypol for $4 \mathrm{~h}$. The control and gossypol-treated cells were lysed with RIPA lysis buffer $(50 \mathrm{mM}$ Tris- $\mathrm{HCl}, 150 \mathrm{mM} \mathrm{NaCl}$, $0.1 \%$ SDS, $1 \%$ NP-40, $0.5 \%$ sodium deoxycholate, $1 \mathrm{mM}$ PMSF, protease inhibitors, and phosphatase inhibitors 1 from Solabio (Beijing, China)) for $30 \mathrm{~min}$ on ice. The supernatant was collected after centrifugation for $30 \mathrm{~min}$ at $4^{\circ} \mathrm{C}$. Protein concentrations were determined using a BCA assay. Proteins were separated by $1 \mathrm{D}$ SDS-PAGE and transferred onto a PVDF membrane by electroblotting. After blocking with 5\% nonfat milk for $2 \mathrm{~h}$ at room temperature, the membrane was incubated overnight at $4^{\circ} \mathrm{C}$ with 2000 -fold diluted primary antibody (rabbit anti-YAP1, from Abcam, UK), washed with TBST buffer for 3 times (each 10 minutes), and then incubated for $2 \mathrm{~h}$ with 2000 -fold diluted anti-rabbit secondary antibody labeled with HRP. After washing with TBST buffer for 3 times (each $10 \mathrm{~min}$ ), images were developed using Enlight western blotting detection reagents from Engreen Biosystem (Beijing, China). $\beta$-Actin was detected with anti- $\beta$-actin antibodies as an internal control.

2.7. Quantitative Real-Time PCR ( $q P C R)$. HOCla cells were seeded in $100 \mathrm{~mm}$ plate $\left(1 \times 10^{6}\right.$ cells each) for $24 \mathrm{~h}$ and treated with $10 \mu \mathrm{M}$ gossypol for an additional 4 hours. The total RNA was extracted from each sample using Trizol reagent (Invitrogen, Carlsbad, CA) according to the manufacturer's instructions. RNA quality was examined by agarose gel electrophoresis. Concentrations of RNA were determined using ultraviolet photometry and were immediately transcribed into cDNA using Tiangen 1st strand cDNA synthesis kit from Tiangen (Beijing, China). Specific PCR primers were designed using the Primer-Blast tool (http://www.ncbi.nlm .nih.gov/tools/primer-blast/). These primers are listed in Supplementary Table 1 available online at http://dx.doi.org/ 10.1155/2014/123482. Quantitative real-time PCR was performed using SYBR green master mix (Tiangen, Beijing, China) on Roche 480 instrument (Roche, Rotkreuz, Switzerland). Amplification was performed using the following cycles: denaturation at $94^{\circ} \mathrm{C}, 2 \mathrm{~min}$; amplification at $94^{\circ} \mathrm{C}$ for $15 \mathrm{~s}, 55^{\circ} \mathrm{C}$ for $15 \mathrm{~s}$, and $68^{\circ} \mathrm{C}$ for $15 \mathrm{~s}$ with 40 cycles; followed by a final extension at $72^{\circ} \mathrm{C}$ for $10 \mathrm{~min}$. $\beta$-Actin was used as internal control. The ratio of mRNA level was showed as $2^{-\Delta \Delta \mathrm{CT}}$. The experiment was repeated three times.

2.8. Statistical Analysis. To compare two groups, Student's $t$ test was used. Differences with $P<0.05$ were considered statistically significant.

\section{Results}

3.1. Gossypol-Induced Apoptosis of HOCla Cells. HOCla cells were treated with gossypol at different concentrations for different periods of time. FACS analysis was performed to determine apoptosis and DNA fragmentation in gossypoltreated HOCla cells by propidium iodide staining. Gossypol treatment increases the cell population in the $\mathrm{M} 1$ area 


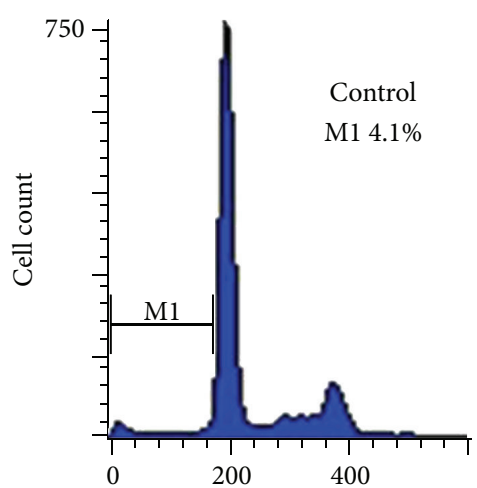

(a)

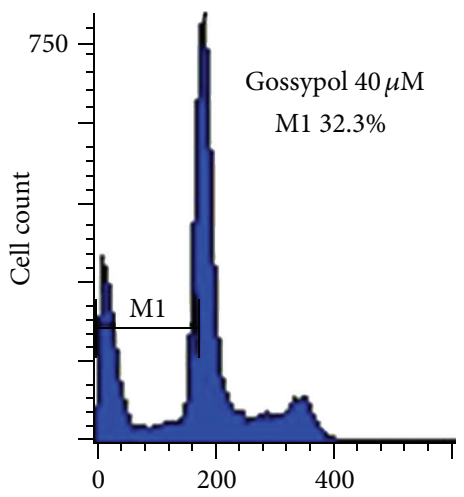

(c)

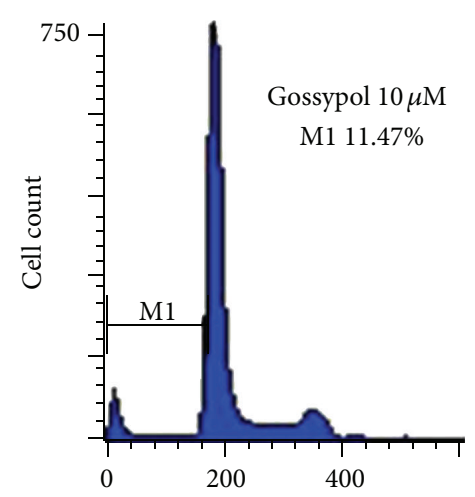

(b)

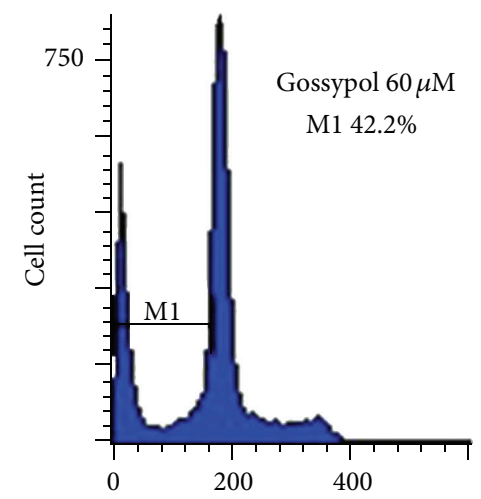

(d)

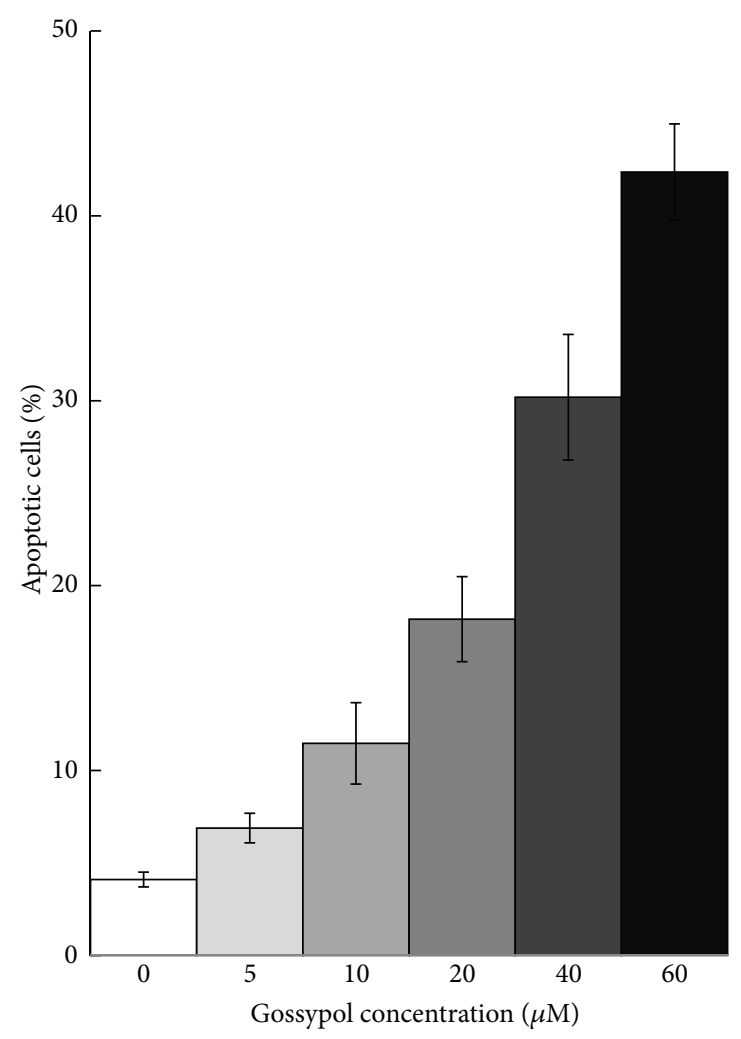

(e)

FIGURE 1: FACS analysis of gossypol-induced apoptosis in HOCla cells. The histogram of PI staining for (a) control; (b) $10 \mu \mathrm{M}$ gossypoltreated cells for 24 hours; (c) $40 \mu \mathrm{M}$ gossypol-treated cells for 24 hours; and (d) $60 \mu \mathrm{M}$ gossypol-treated cells for 24 hours; (e) percentage of apoptosis related cell death in HOCla cells treated with gossypol at different concentrations for 24 hours. Results are expressed as the mean of three experiments. Significant apoptosis was induced.

compared to untreated cells. Concomitantly, the population of healthy cells was decreased. The quantitative FACS data representing the percentage of live and apoptotic cells based on DNA fragmentation are shown in Figure 1. We estimated the percentage of apoptotic cells reached $42 \%$ after cells were treated with $60 \mu \mathrm{M}$ gossypol for $24 \mathrm{~h}$.

\subsection{Phosphoproteomic Analysis of Vehicle Control and Gossy-} pol-Treated HOCla Cells. In the present study, we focused on changes in phosphorylation of HOCla cells upon $10 \mu \mathrm{M}$ gossypol treatment for $4 \mathrm{~h}$. Using the high confidence score filter, we identified 9754 and 9540 phosphopeptides, respectively, in untreated and gossypol-treated cells, leading to identification of 3032 and 3092 phosphoproteins. Experiments were repeated three times and 62 phosphoproteins with higher scores were chosen (Supplementary Table 2) and their phosphorylation sites were further confirmed by Scaffold PTM-Proteome Software. Gene Ontology (GO) was used to categorize the identified phosphoproteins into several significant groups including RNA binding and processing, cytoskeletal organization, and transcription regulation (Supplementary Figure 1). Many of them also play crucial roles in various physiological and pathological processes. For example, Isoform 1 of Bcl-2-associated transcription factor
1 and interferon gamma-inducible protein 16 regulate cell apoptosis.

The MS/MS spectrum of each identified phosphopeptide was manually confirmed. For example, the MS/MS spectra matched to phosphopeptides of YAP1 and Isoform 1 of Akinase anchor protein 12 are displayed in Figure 2, respectively. In Figures 2(a) and 2(b), a loss of phosphate group $(-98)$ was observed for both peptides indicating that peptides contain phosphorylated Ser or Thr residues. By matching b and $y$ ions of the phosphorylated peptides, we identified that the underlined Ser residue in GDSETDLEALFNAVMNPK was phosphorylated in YAP1 (Figure 2(a)); so was the underlined Thr- 6 residue in SAESPTSPVTSETGSTFK in AKAP12 (Figure 2(b)). Using the same score cutoff filter, 63 phosphoproteins were identified in three repeated experiments from gossypol-treated cells (Supplementary Table 3). In comparison to phosphorylated proteins identified in control, phosphorylation of 29 proteins changes upon gossypol treatment (Table 1). Using a label-free quantitation method, we semiquantified the fold change of phosphopeptides for 7 proteins (Figure 3). Intensities of phosphopeptides from Isoform 1 of A-kinase anchor protein 12 (AKAP12), Plastin-2, Brefeldin A-inhibited guanine nucleotide-exchange protein 2, YAP1, Nascent polypeptide-associated complex subunit 


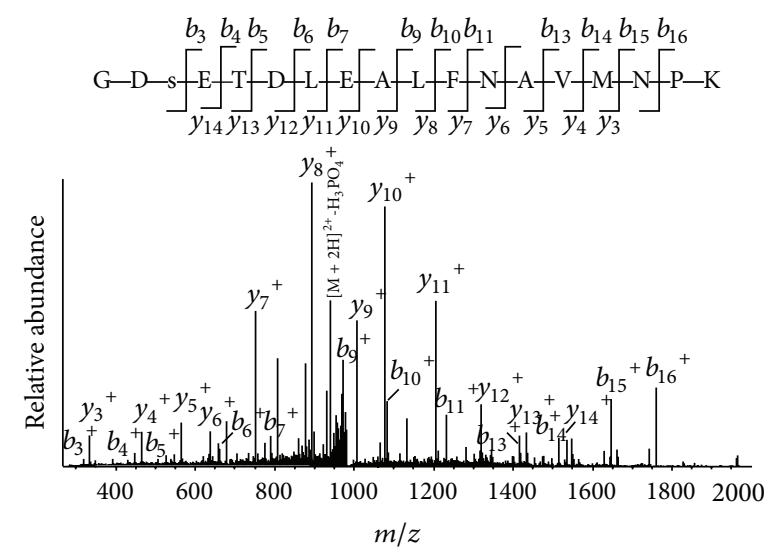

(a)

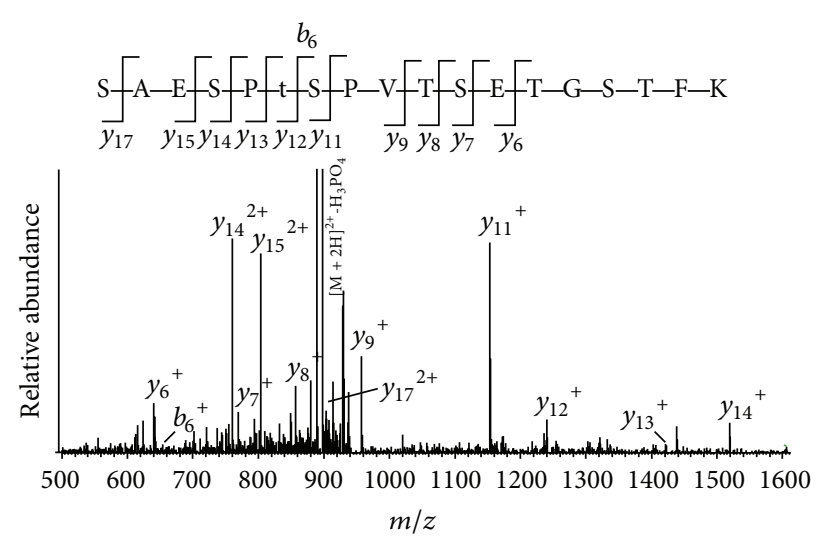

(b)

FIGURE 2: MS/MS spectra for identification of protein phosphorylation sites. (a) The MS/MS spectrum of a doubly charged peptide ion at $m / z$ 1015.94 for $\mathrm{MH}_{2}^{2+}$ corresponding to the mass of the peptide GDSETDLEALFNAVMNPK from YAP1. (b) The MS/MS spectrum of a doubly charged peptide ion at $m / z 946.91$ for $\mathrm{MH}_{2}^{2+}$ corresponding to the mass of the peptide SAESPTSPVTSETGSTFK from Isoform 1 of A-kinase anchor protein 12 . The underlined residues are the phosphorylation sites.

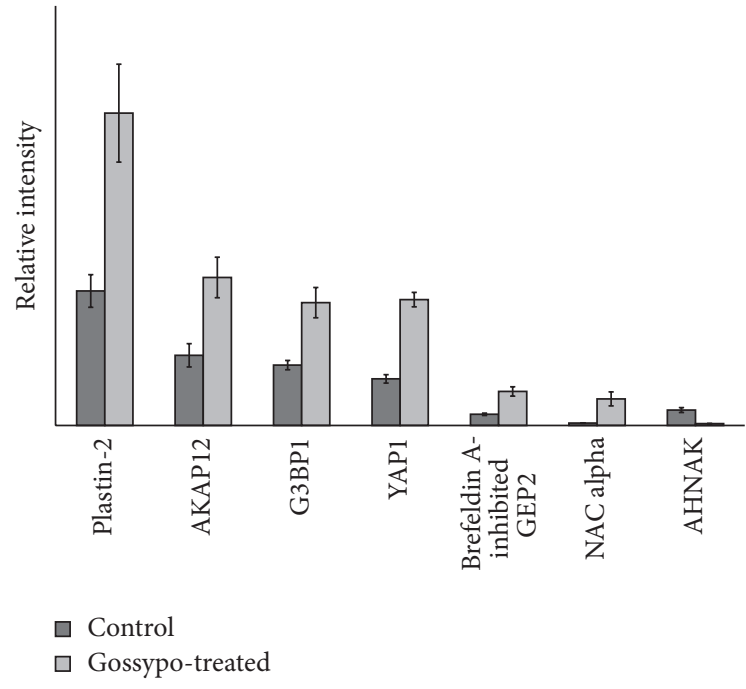

FIGURE 3: The relative abundance and fold changes of Isoform 1 of Akinase anchor protein 12 (AKAP12), Plastin-2, Brefeldin A-inhibited guanine nucleotide-exchange protein 2, YAP1, Nascent polypeptideassociated complex subunit alpha, Ras GTPase-activating proteinbinding protein 1 (G3BP1), and neuroblast differentiation-associated protein (AHNAK) from the untreated and gossypol-treated HOCla cells. Cells treated with DMSO were used as the control.

alpha, and Ras GTPase-activating protein-binding protein 1 (G3BP1) increase while that of neuroblast differentiationassociated protein (AHNAK) decreases after gossypol treatment.

To examine whether phosphorylation changes are due to expression changes of the respective proteins, western blot and qPCR were used to quantify protein expressions and levels of mRNA in selected proteins. Western blotting of YAP1 (Figure 4(a)) showed that gossypol treatment does not induce upregulation of YAP1. This is also confirmed by qPCR analysis of YAP1 (Figure 4(b)). Data showed that the mRNA level of AKAP12 does not change, but that of G3BP1 increases upon gossypol treatment. To explore if the increased phosphorylation in YAP1, AKAP12, and Plastin is associated with their upstream regulators, we have also employed qPCR to quantify the mRNA expressions of LATS1, ATM, and ATR, showing that gossypol induced upregulation of LATS1, ATM, and ATR (Figure 5).

\section{Discussion}

Gossypol is one of the anticancer drugs in development. Studies have shown that gossypol targets a complex spectrum of proteins including $\mathrm{Bcl}-2$ and signaling pathways. In the present study, we show that gossypol effectively induces apoptosis in ovarian cancer cells. Using a phosphoproteomic approach, we identified that gossypol treatment induced changes in phosphorylation of proteins associated with YAP1Hippo pathway and cytoskeletal organization. To the best of our knowledge, this is the first report suggesting that gossypol-induced apoptosis is associated with phosphorylation of YAP1 and other actin-binding proteins.

Using HOCla cells as a model system for ovarian cancer, we found that $42 \%$ of HOCla cells went into apoptosis in response to $60 \mu \mathrm{M}$ gossypol treatment for 24 hours. We carried out a phosphoproteomic analysis to compare phosphoproteins between the untreated and gossypol-treated HOCla cells. We identified about 9700 phosphopeptides at $1 \%$ false discovery rate. We only chose 62 phosphoproteins that were identified in three repeated experiments with higher scores (Supplementary Table 2) and their phosphorylation sites were confirmed by Scaffold PTM-Proteome Software and PhosphoRS that is an algorithm to determine individual site probabilities for each putative phosphorylation site. Using the same filter settings, we also identified 63 phosphoproteins from gossypol-treated cells, in which phosphorylation of 29 proteins changes with gossypol treatment 
TABLE 1: Gossypol-induced changes of phosphoproteins in HOCla cells.

\begin{tabular}{|c|c|c|c|c|}
\hline IPI accession & Protein name & Peptide sequence & Control & $\begin{array}{l}\text { Gossypol- } \\
\text { treated }\end{array}$ \\
\hline IPI00002186 & $\begin{array}{l}\text { Brefeldin A-inhibited guanine } \\
\text { nucleotide-exchange protein } 2\end{array}$ & GSSLSGTDDGAQEVVKDILEDVVTSAIK & + & ++ \\
\hline IPI00008529 & $60 \mathrm{~S}$ acidic ribosomal protein $\mathrm{P} 2$ & KEESEEESDDDMGFGLFD & & + \\
\hline IPI00237884 & $\begin{array}{l}\text { Isoform } 1 \text { of A-kinase anchor } \\
\text { protein } 12\end{array}$ & SAESPTSPVTSETGSTFK & + & ++ \\
\hline IPI00185919 & Isoform 1 of La-related protein 1 & GLSASLLPDLDSENWIEVK & & + \\
\hline IPI00015953 & $\begin{array}{l}\text { Isoform } 1 \text { of nucleolar RNA } \\
\text { helicase } 2\end{array}$ & NEEPSEEEIDAPKPK & & + \\
\hline IPI00102752 & $\begin{array}{l}\text { Isoform } 1 \text { of putative } \\
\text { RNA-binding protein } 15\end{array}$ & SLSPGGAALGYR & & + \\
\hline IPI00451401 & $\begin{array}{l}\text { Isoform } 2 \text { of triosephosphate } \\
\text { isomerase }\end{array}$ & KQSLLGELIGTLNAAK & & + \\
\hline IPI00293312 & $\begin{array}{l}\text { Isoform } 2 \text { of zinc finger } \mathrm{CCCH} \\
\text { domain-containing protein } 18\end{array}$ & LGVSVISPR & & + \\
\hline IPI00023748 & $\begin{array}{l}\text { Nascent polypeptide-associated } \\
\text { complex subunit alpha }\end{array}$ & VQGEAVSNIQENTQTPTVQEESEEEEEVDETGVEVK & + & ++ \\
\hline IPI00604756 & $\begin{array}{l}\text { Nuclear receptor-binding } \\
\text { protein }\end{array}$ & TPTPEPAEVETR & & + \\
\hline IPI00010471 & Plastin-2 & GSVSSDEEMMELR & + & ++ \\
\hline IPI00015029 & Prostaglandin E synthase 3 & DWEDDSDDEDMSNFDR & & + \\
\hline IPI00012442 & $\begin{array}{l}\text { Ras GTPase-activating } \\
\text { protein-binding protein } 1\end{array}$ & SSSPAPADIAQTVQEDLR & + & ++ \\
\hline IPI00008708 & $\begin{array}{l}\text { Ribosomal L1 } \\
\text { domain-containing protein } 1\end{array}$ & ATNESEDEIPQLVPIGK & & + \\
\hline IPI00029601 & Src substrate cortactin & $\begin{array}{l}\text { LPSSPVYEDAASFK; TQTPPVSPAPQPTEER; } \\
\text { TQTPPV } \underline{P} P A P Q P T E E R\end{array}$ & & + \\
\hline IPI00045051 & $\begin{array}{l}\text { Transcriptional activator } \\
\text { protein Pur-beta }\end{array}$ & DSLGDFIEHYAQLGPSSPPEQLAAGAEEGGGPR & & + \\
\hline IPI00009326 & Yes-associated protein beta & GDSEETDLEALFNAVMNPK & + & ++ \\
\hline IPI00844578 & $\begin{array}{l}\text { ATP-dependent RNA helicase } \\
\text { A }\end{array}$ & SEEVPAFGVAS्SPPLTDTPDTTANAEGDLPTTMGGPLPPHLALK & + & \\
\hline IPI00010463 & GTP-binding protein 1 & GLGPPSPPAPPR & + & \\
\hline IPI00009505 & Isoform 1 of beta-2-syntrophin & GLGPPSPPAPPR & + & \\
\hline IPI00216049 & $\begin{array}{l}\text { Isoform } 1 \text { of heterogeneous } \\
\text { nuclear ribonucleoprotein } \mathrm{K}\end{array}$ & METEQPEETFPNTETNGEFGK & + & \\
\hline IPI00019848 & Isoform 1 of host cell factor 1 & SQCQTRQTSATSSTTMTVMATGAPCŚSAGPLLGPSMAREPGGR & + & \\
\hline IPI00782992 & $\begin{array}{l}\text { Isoform } 1 \text { of serine/arginine } \\
\text { repetitive matrix protein } 2\end{array}$ & MALPPQEDATASPPP; THTTALAGRSPSPASGR & + & \\
\hline IPI00026466 & $\begin{array}{l}\text { Isoform } 2 \text { of nipped-B-like } \\
\text { protein }\end{array}$ & AITSLLGGGS్PR & + & \\
\hline IPI00150057 & $\begin{array}{l}\text { Isoform } 2 \text { of SWI/SNF complex } \\
\text { subunit SMARCC2 }\end{array}$ & DMDEPSPVPNVEEVTLPK & + & \\
\hline IPI00165041 & Isoform 6 of treacle protein & TSQVGAASAPAKESPR & + & \\
\hline IPI00006122 & $\begin{array}{l}\text { Isoform MEA6 of cutaneous } \\
\text { T-cell lymphoma-associated } \\
\text { antigen } 5\end{array}$ & AFLSPPTLLEGPLR & + & \\
\hline IPI00164672 & mRNA-decapping enzyme $1 \mathrm{~A}$ & HAPTYTIPLSPVLSPTLPAEAPTAQVPPSLPR & + & \\
\hline IPI00103483 & Negative elongation factor B & KPSPAQAAETPALELPLPSVPAPAPL & + & \\
\hline IPI00021812 & $\begin{array}{l}\text { Neuroblast } \\
\text { differentiation-associated } \\
\text { protein AHNAK }\end{array}$ & FKAEAPLPSPK & ++ & + \\
\hline
\end{tabular}




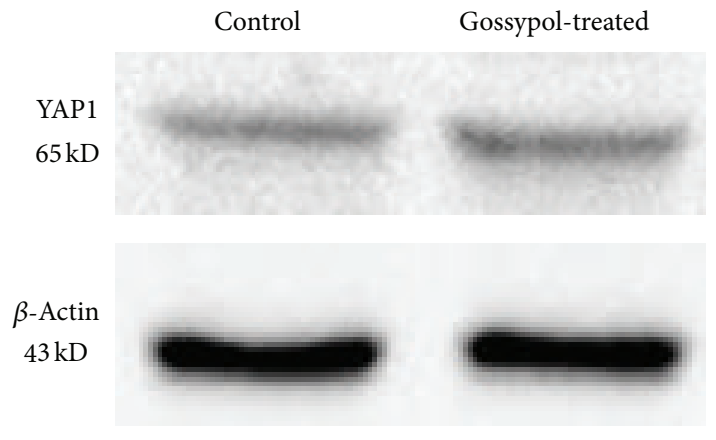

(a)

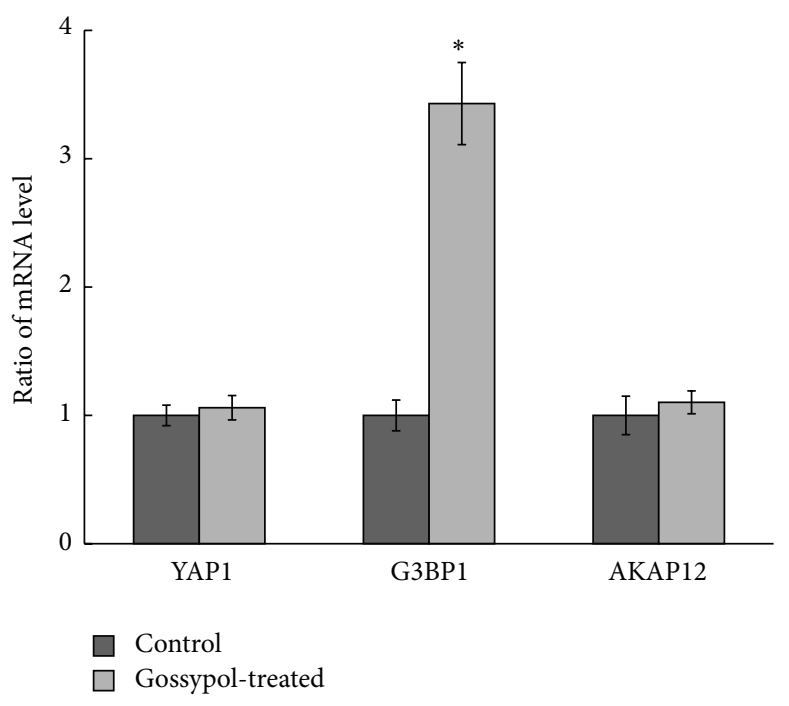

(b)

FIGURE 4: (a) Western blot showed that gossypol treatment does not induce upregulation of YAP1. Cells treated with DMSO were used as the control, and actin was used as protein loading control. (b) qPCR analysis of expressions levels of YAP1, AKAP12, and G3BP1. ${ }^{*}$ represents $P<0.05$. Cells treated with DMSO were used as the control.

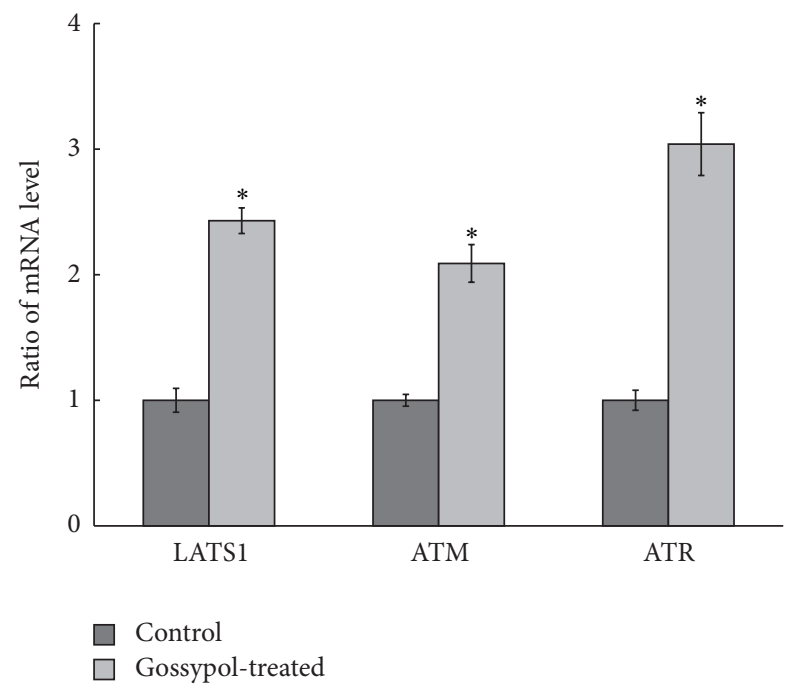

FIGURE 5: qPCR analysis of expressions levels of LATS1, ATM, and ATR. ${ }^{*}$ represents $P<0.05$. Cells treated with DMSO were used as the control.

as listed in Table 1. Using label-free quantitation, we analyzed the fold changes of phosphopeptides from 7 proteins (Figure 3): AKAP12, Plastin-2, Brefeldin A-inhibited guanine nucleotide-exchange protein 2, YAP1, Nascent polypeptideassociated complex subunit alpha, G3BP1, and AHNAK.

YAP1 is the transcriptional coactivator in the Hippo signaling pathway and is an oncogene in ovarian cancer by enhancing the transformed phenotype of ovarian cancer cell lines and conferring resistance to chemotherapeutic agents that are commonly used to treat ovarian cancer [4548]. The high nuclear YAP expression was also found to be correlated with poor patient prognosis in the invasive epithelial ovarian cancer samples. This is because nuclear YAP is associated with regulation of cellular genes important for cell proliferation, cell death, cell migration, and epithelial mesenchymal transition. YAP proteins are phosphorylated by LATS kinases on multiple sites in the Hippo pathway. The phosphorylation of YAP resulted in repressing YAP activity by retention of YAP in the cytoplasm and targeting YAP protein for ubiquitin-mediated proteolysis. YAP1 contains five LATS-targeted consensus phosphorylation sequences (Hx[HRK] $\mathrm{xx}[\mathrm{ST}])$ at positions 61, 109, 127, 164, and 397 [49]. We identified phosphorylation at Ser 61 (Figure 2(a)) that increases upon gossypol treatment.

By western blot and qPCR analysis, the expression of YAP1 was found to remain unchanged (Figure 4). However, qPCR analysis showed that the mRNA level of LATS increased with gossypol treatment (Figure 4). This indicates that gossypol-induced upregulation of LATS targets YAP1 phosphorylation at Ser 61 residue in HOCla cells, and, in turn, an increase of YAP phosphorylation leads to retention of YAP1 in cytoplasm to reduce cell proliferation. A recent study also revealed that G-protein-coupled receptors act upstream of the transcriptional coactivators YAP/TAZ and demonstrated that the Hippo signaling pathway regulates the actin cytoskeletal organization [50]. Therefore, we hypothesize that alternation of YAP1 phosphorylation contributes to gossypolinduced cell death through retention of YAP1 in cytoplasm and/or changes of the actin cytoskeletal organization.

Gossypol also induced phosphorylation changes in several actin-binding proteins including Src substrate cortactin, AHNAK, Plastin, and AKAP12. AHNAK is a giant propellerlike protein that translocates from cytosol to the plasma membrane to form a multimeric complex with actin and annexin 2/S100A10. Cortactin is also a cytoskeletal protein involved in coordinating actin reorganization during cell movement and its amino-terminal acidic domain binds to 
Arp2/3 and WASP complex at F-actin branches. Plastin is an actin-binding protein and is involved in actin filament bundle formation to regulate intracellular protein transport. Moreover, AKAP12 is a scaffold protein that contains 3 conserved PKA binding motifs to assist formation of actinbased cytoskeletal architecture. Studies have shown that AKAP12 is a tumor suppressor and reexpression of AKAP12 inhibits progression and metastasis of colorectal carcinoma [51-53]. Phosphoproteomic analysis has shown that AKAP12 and Plastin are substrates of ATM/ATR kinase [50]. By qPCR analysis, we found that gossypol induces upregulation of ATM and ATR gene expressions, indicating that gossypol induces upregulation of ATM to increase phosphorylation of AKAP12. Although we have not identified the ATM/ATRtargeted phosphorylation sites in AKAP12 and Plastin, our data suggest that phosphorylation changes of these actinbinding proteins affect the actin cytoskeletal organization and play a role in gossypol-induced cell death [54].

Taken together, we showed that gossypol induces apoptosis of ovarian cancer cells. Proteomic analysis of untreated and gossypol-treated cells reveals that gossypol induces phosphorylation changes in 29 proteins including YAP1 and AKAP12. Our results suggest that gossypol targets the actin cytoskeletal organization to induce ovarian cancer cell death through changing phosphorylation states of actin-binding proteins and activating YAP1-associated Hippo pathway.

\section{Conflict of Interests}

The authors declare that there is no conflict of interests regarding the publication of this paper.

\section{Acknowledgments}

The authors thank the Cell Biology Facility and the Protein Chemistry Facility at the Center for Biomedical Analysis of Tsinghua University for sample analysis. They thank Dr. Heng Cui of Peking University People's Hospital for providing HOCla cell line. This work was supported by NSFC 30871434 (R.S.G.).

\section{References}

[1] D. Bell, A. Berchuck, M. Birrer et al., "Integrated genomic analyses of ovarian carcinoma," Nature, vol. 474, no. 7353, pp. 609615, 2011.

[2] D. S. Miller, J. A. Blessing, C. N. Krasner et al., “ Phase II evaluation of pemetrexed in the treatment of recurrent or persistent platinum-resistant ovarian or primary peritoneal carcinoma: a study of the Gynecologic Oncology Group," Journal of Clinical Oncology, vol. 27, no. 16, pp. 2686-2691, 2009.

[3] A. Jemal, R. Siegel, E. Ward, Y. Hao, J. Xu, and M. J. Thun, "Cancer statistics, 2009," CA: A Cancer Journal for Clinicians, vol. 59, no. 4, pp. 225-249, 2009.

[4] A. A. Ahmed, D. Etemadmoghadam, J. Temple et al., "Driver mutations in TP53 are ubiquitous in high grade serous carcinoma of the ovary," The Journal of Pathology, vol. 221, no. 1, pp. 49-56, 2010.
[5] F. Tas, D. Duranyildiz, H. Oguz, H. Camlica, V. Yasasever, and E. Topuz, "The value of serum bcl-2 levels in advanced epithelial ovarian cancer," Medical Oncology, vol. 23, no. 2, pp. 213-217, 2006.

[6] N. S. Anderson, L. Turner, S. Livingston, R. Chen, S. V. Nicosia, and P. A. Kruk, "Bcl-2 expression is altered with ovarian tumor progression: an immunohistochemical evaluation," Journal of Ovarian Research, vol. 2, no. 1, article 16, 2009.

[7] A. M. Petros, A. Medek, D. G. Nettesheim et al., "Solution structure of the antiapoptotic protein bcl-2," Proceedings of the National Academy of Sciences of the United States of America, vol. 98, no. 6, pp. 3012-3017, 2001.

[8] M. Sattler, H. Liang, D. Nettesheim et al., "Structure of Bcl$\mathrm{x}(\mathrm{L})$-Bak peptide complex: recognition between regulators of apoptosis," Science, vol. 275, no. 5302, pp. 983-986, 1997.

[9] A. M. Petros, D. G. Nettesheim, Y. Wang et al., "Rationale for Bcl-xL/Bad peptide complex formation from structure, mutagenesis, and biophysical studies," Protein Science, vol. 9, no. 12, pp. 2528-2534, 2000.

[10] J. Wang, D. Liu, Z. Zhang et al., "Structure-based discovery of an organic compound that binds Bcl-2 protein and induces apoptosis of tumor cells," Proceedings of the National Academy of Sciences of the United States of America, vol. 97, no. 13, pp. 7124$7129,2000$.

[11] A. Degterev, A. Lugovskoy, M. Cardone et al., "Identification of small-molecule inhibitors of interaction between the $\mathrm{BH} 3$ domain and Bcl-xL," Nature Cell Biology, vol. 3, no. 2, pp. 173182,2001

[12] S. Tzung, K. M. Kim, G. Basãez et al., "Antimycin A mimics a cell-death-inducing Bcl-2 homology domain 3," Nature Cell Biology, vol. 3, no. 2, pp. 183-191, 2001.

[13] G. Wang, Z. Nikolovska-Coleska, C. Yang et al., "Structurebased design of potent small-molecule inhibitors of anti-apoptotic Bcl-2 proteins," Journal of Medicinal Chemistry, vol. 49, no. 21, pp. 6139-6142, 2006.

[14] C. L. Oliver, M. B. Miranda, S. Shangary, S. Land, S. Wang, and D. E. Johnson, "(-)-gossypol acts directly on the mitochondria to overcome Bcl-2- and Bcl-XL-mediated apoptosis resistance," Molecular Cancer Therapeutics, vol. 4, no. 1, pp. 23-31, 2005.

[15] V. Voss, C. Senft, V. Lang et al., "The pan-Bcl-2 inhibitor (-)gossypol triggers autophagic cell death in malignant glioma," Molecular Cancer Research, vol. 8, no. 7, pp. 1002-1016, 2010.

[16] J. Lian, X. Wu, F. He et al., "A natural BH3 mimetic induces autophagy in apoptosis-resistant prostate cancer via modulating Bcl-2-Beclin1 interaction at endoplasmic reticulum," Cell Death and Differentiation, vol. 18, no. 1, pp. 60-71, 2011.

[17] Y. Meng, W. Tang, Y. Dai et al., "Natural BH3 mimetic (-)-gossypol chemosensitizes human prostate cancer via Bcl-xL inhibition accompanied by increase of Puma and Noxa," Molecular Cancer Therapeutics, vol. 7, no. 7, pp. 2192-2202, 2008.

[18] R. C. Stein, A. E. A. Joseph, S. A. Matlin, D. C. Cunningham, H. T. Ford, and R. C. Coombes, "A preliminary clinical study of gossypol in advanced human cancer," Cancer Chemotherapy and Pharmacology, vol. 30, no. 6, pp. 480-482, 1992.

[19] H. Cheong, C. Lu, T. Lindsten, and C. B. Thompson, "Therapeutic targets in cancer cell metabolism and autophagy," Nature Biotechnology, vol. 30, no. 7, pp. 671-678, 2012.

[20] Y. Yu, J. A. Deck, L. A. Hunsaker et al., "Selective active site inhibitors of human lactate dehydrogenases $\mathrm{A}_{4}, \mathrm{~B}_{4}$, and $\mathrm{C}_{4}^{1}$ ", Biochemical Pharmacology, vol. 62, no. 1, pp. 81-89, 2001. 
[21] A. Le, C. R. Cooper, A. M. Gouw et al., "Inhibition of lactate dehydrogenase A induces oxidative stress and inhibits tumor progression," Proceedings of the National Academy of Sciences of the United States of America, vol. 107, no. 5, pp. 2037-2042, 2010.

[22] J. Jiang, W. Ye, and Y. C. Lin, "Gossypol inhibits the growth of MAT-LyLu prostate cancer cells by modulation of TGF $\beta /$ Akt signaling," International Journal of Molecular Medicine, vol. 24, no. 1, pp. 69-75, 2009.

[23] S. R. Volate, B. T. Kawasaki, E. M. Hurt et al., "Gossypol induces apoptosis by activating p53 in prostate cancer cells and prostate tumor-initiating cells," Molecular Cancer Therapeutics, vol. 9, no. 2, pp. 461-470, 2010.

[24] S. F. Zerp, R. Stoter, G. Kuipers et al., "AT-101, a small molecule inhibitor of anti-apoptotic Bcl-2 family members, activates the SAPK/JNK pathway and enhances radiation-induced apoptosis," Radiation Oncology, vol. 4, article 47, 2009.

[25] Z. Hu, J. Sun, X. Zhu, D. Yang, and Y. Zeng, "ApoG2 induces cell cycle arrest of nasopharyngeal carcinoma cells by suppressing the c-Myc signaling pathway," Journal of Translational Medicine, vol. 7, article 74, 2009.

[26] D. Moon, M. Kim, J. Lee, and G. Kim, "Gossypol suppresses NF- $\kappa$ B activity and NF- $\kappa$ B-related gene expression in human leukemia U937 cells," Cancer Letters, vol. 264, no. 2, pp. 192200, 2008.

[27] C. Ko, S. Shen, L. Yang, C. Lin, and Y. Chen, "Gossypol reduction of tumor growth through ROS-dependent mitochondria pathway in human colorectal carcinoma cells," International Journal of Cancer, vol. 121, no. 8, pp. 1670-1679, 2007.

[28] B. Sung, J. Ravindran, S. Prasad, M. K. Pandey, and B. B. Aggarwal, "Gossypol induces death receptor-5 through activation of the ROS-ERK-CHOP pathway and sensitizes colon cancer cells to TRAIL," The Journal of Biological Chemistry, vol. 285, no. 46, pp. 35418-35427, 2010.

[29] M. J. Sikora, J. A. Bauer, M. Verhaegen et al., "Anti-oxidant treatment enhances anti-tumor cytotoxicity of (-)-gossypol," Cancer Biology and Therapy, vol. 7, no. 5, pp. 769-778, 2008.

[30] J. Cheng, Y. Lo, J. Yeh et al., "Effect of gossypol on intracellular $\mathrm{Ca}^{2+}$ regulation in human hepatoma cells," Chinese Journal of Physiology, vol. 46, no. 3, pp. 117-122, 2003.

[31] X. Pang, Y. Wu, B. Lu et al., "(-)-Gossypol suppresses the growth of human prostate cancer xenografts via modulating VEGF signaling-mediated angiogenesis," Molecular Cancer Therapeutics, vol. 10, no. 5, pp. 795-805, 2011.

[32] U. Varol, B. Karaca, D. Tunali et al., "The effect of racemic gossypol and AT-101 on angiogenic profile of OVCAR-3 cells: a preliminary molecular framework for gossypol enantiomers," Experimental Oncology, vol. 31, no. 4, pp. 220-225, 2009.

[33] G. L. Johnson and R. Lapadat, "Mitogen-activated protein kinase pathways mediated by ERK, JNK, and p38 protein kinases," Science, vol. 298, no. 5600, pp. 1911-1912, 2002.

[34] T. Hunter, "Protein kinases and phosphatases: The yin and yang of protein phosphorylation and signaling," Cell, vol. 80 , no. 2 , pp. 225-236, 1995.

[35] Y. Tanaka, Y. Terai, A. Tanabe et al., "Prognostic effect of epidermal growth factor receptor gene mutations and the aberrant phosphorylation of Akt and ERK in ovarian cancer," Cancer Biology and Therapy, vol. 11, no. 1, pp. 50-57, 2011.

[36] D. A. Altomare, Q. W. Hui, K. L. Skele et al., "AKT and mTOR phosphorylation is frequently detected in ovarian cancer and can be targeted to disrupt ovarian tumor cell growth," Oncogene, vol. 23, no. 34, pp. 5853-5857, 2004.
[37] Q. Y. Zeng, M. Sun, R. I. Feldman et al., "Frequent activation of AKT2 and induction of apoptosis by inhibition of phosphoinositide-3-OH kinase/Akt pathway in human ovarian cancer," Oncogene, vol. 19, no. 19, pp. 2324-2330, 2000.

[38] L. Shayesteh, Y. Lu, W. L. Kuo et al., "PlK3CA is implicated as an oncogene in ovarian cancer," Nature Genetics, vol. 21, no. 1, pp. 99-102, 1999.

[39] P. K. Kandala and S. K. Srivastava, "Diindolylmethane suppresses ovarian cancer growth and potentiates the effect of cisplatin in tumor mouse model by targeting signal transducer and activator of transcription 3 (STAT3)," BMC Medicine, vol. 10, article 9, 2012.

[40] M. Huang, C. Page, R. K. Reynolds, and J. Lin, "Constitutive activation of Stat 3 oncogene product in human ovarian carcinoma cells," Gynecologic Oncology, vol. 79, no. 1, pp. 67-73, 2000.

[41] Z. Duan, R. Foster, D. A. Bell et al., "Signal transducers and activators of transcription 3 pathway activation in drug-resistant ovarian cancer," Clinical Cancer Research, vol. 12, no. 17, pp. 5055-5063, 2006.

[42] H. C. Harsha and A. Pandey, "Phosphoproteomics in cancer," Molecular Oncology, vol. 4, no. 6, pp. 482-495, 2010.

[43] K. Schmelzle and F. M. White, "Phosphoproteomic approaches to elucidate cellular signaling networks," Current Opinion in Biotechnology, vol. 17, no. 4, pp. 406-414, 2006.

[44] T. E. Thingholm, T. J. D. Jørgensen, O. N. Jensen, and M. R. Larsen, "Highly selective enrichment of phosphorylated peptides using titanium dioxide," Nature Protocols, vol. 1, no. 4, pp. 1929-1935, 2006.

[45] B. Zhao, L. Li, Q. Lei, and K. Guan, "The Hippo-YAP pathway in organ size control and tumorigenesis: an updated version," Genes and Development, vol. 24, no. 9, pp. 862-874, 2010.

[46] V. A. Codelia and K. D. Irvine, "Hippo signaling goes long range," Cell, vol. 150, no. 4, pp. 669-670, 2012.

[47] H. McNeill, M. Sudol, G. Halder, S. Strano, G. Blandino, and Y. Shaul, "The Hippo tumor suppressor pathway: a report on the second workshop on the Hippo tumor suppressor pathway," Cell Death and Differentiation, vol. 18, no. 8, pp. 1388-1390, 2011.

[48] X. Zhang, J. George, S. Deb et al., "The Hippo pathway transcriptional co-activator, YAP, is an ovarian cancer oncogene," Oncogene, vol. 30, no. 25, pp. 2810-2822, 2011.

[49] Y. Hao, A. Chun, K. Cheung, B. Rashidi, and X. Yang, “Tumor suppressor LATS1 is a negative regulator of oncogene YAP," Journal of Biological Chemistry, vol. 283, no. 9, pp. 5496-5509, 2008.

[50] F. Yu, B. Zhao, N. Panupinthu et al., "Regulation of the HippoYAP pathway by G-protein-coupled receptor signaling," Cell, vol. 150, no. 4, pp. 780-791, 2012.

[51] S. Matsuoka, B. A. Ballif, A. Smogorzewska et al., "ATM and ATR substrate analysis reveals extensive protein networks responsive to DNA damage," Science, vol. 316, no. 5828, pp. 1160 1166, 2007.

[52] M. Choi, H. Jong, T. Y. Kim et al., "AKAP12/gravin is inactivated by epigenetic mechanism in human gastric carcinoma and shows growth suppressor activity," Oncogene, vol. 23, no. 42, pp. 7095-7103, 2004.

[53] W. Liu, M. Guan, T. Hu, X. Gu, and Y. Lu, "Re-Expression of AKAP12 inhibits progression and metastasis potential of colorectal carcinoma in vivo and in vitro," PLoS ONE, vol. 6, no. 8, Article ID e24015, 2011.

[54] P. Reddy, M. Deguchi, Y. Cheng, and A. J. W. Hsueh, "Actin cytoskeleton regulates hippo signaling," PLoS ONE, vol. 8, no. 9, 2013. 

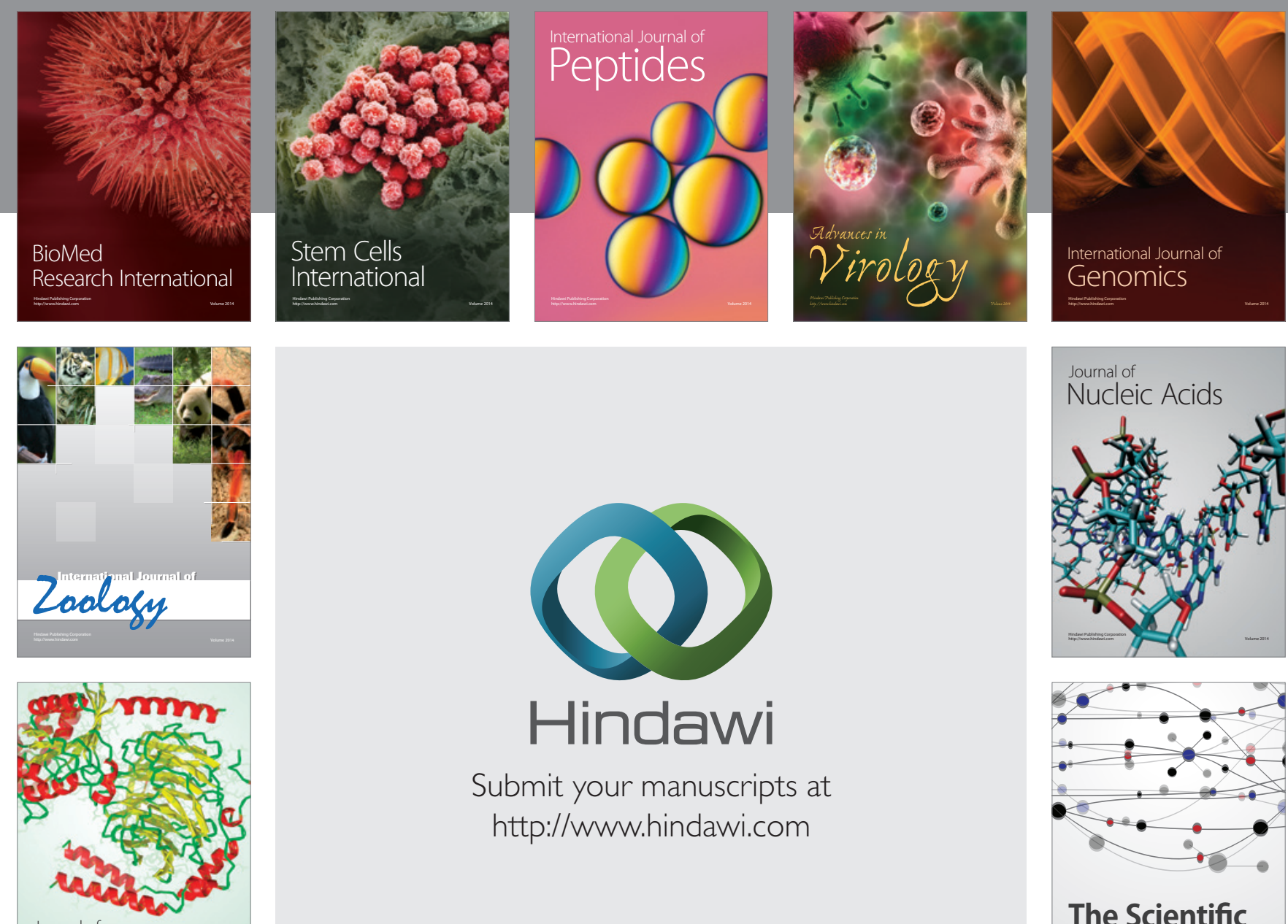

Submit your manuscripts at

http://www.hindawi.com

Journal of
Signal Transduction
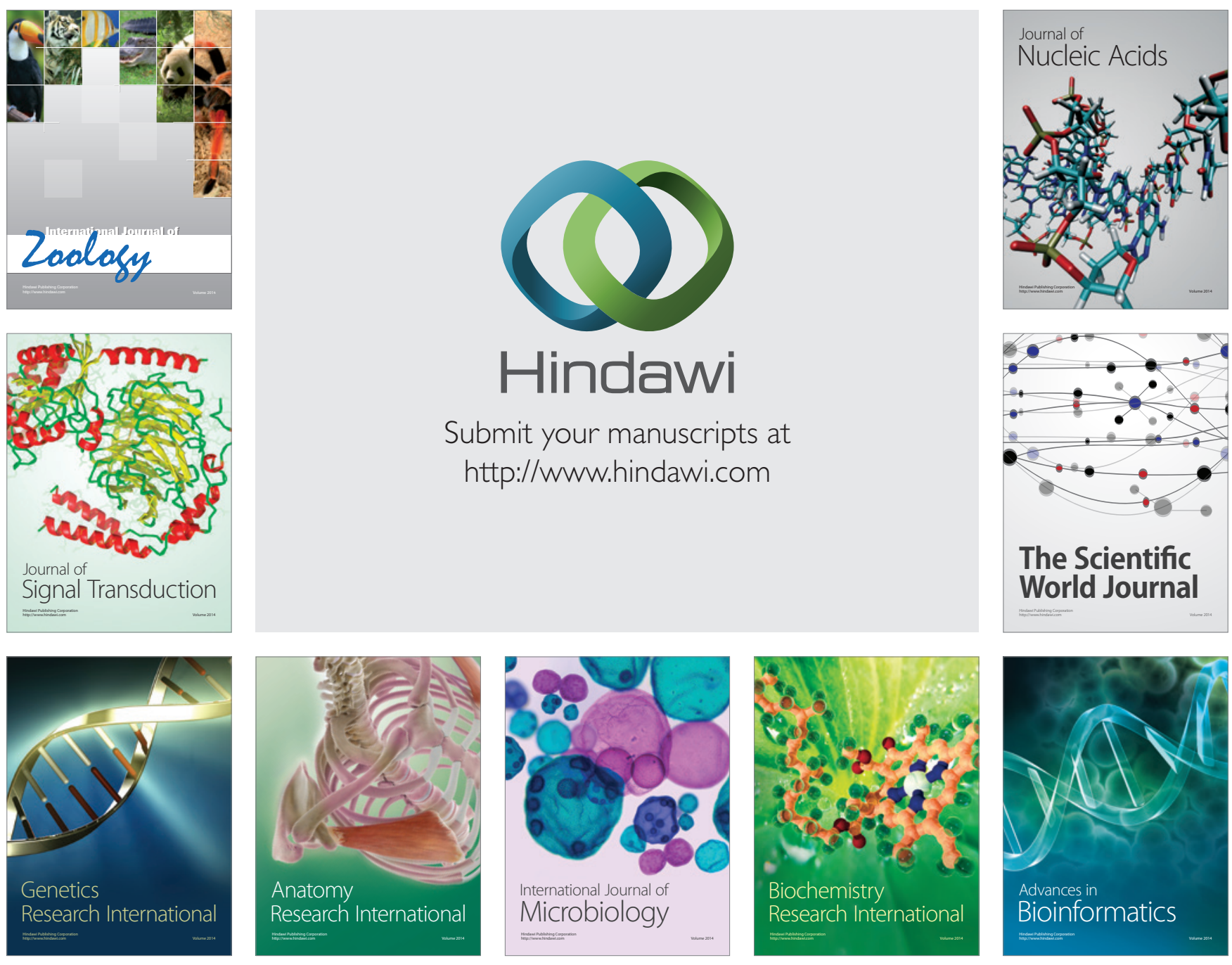

The Scientific World Journal
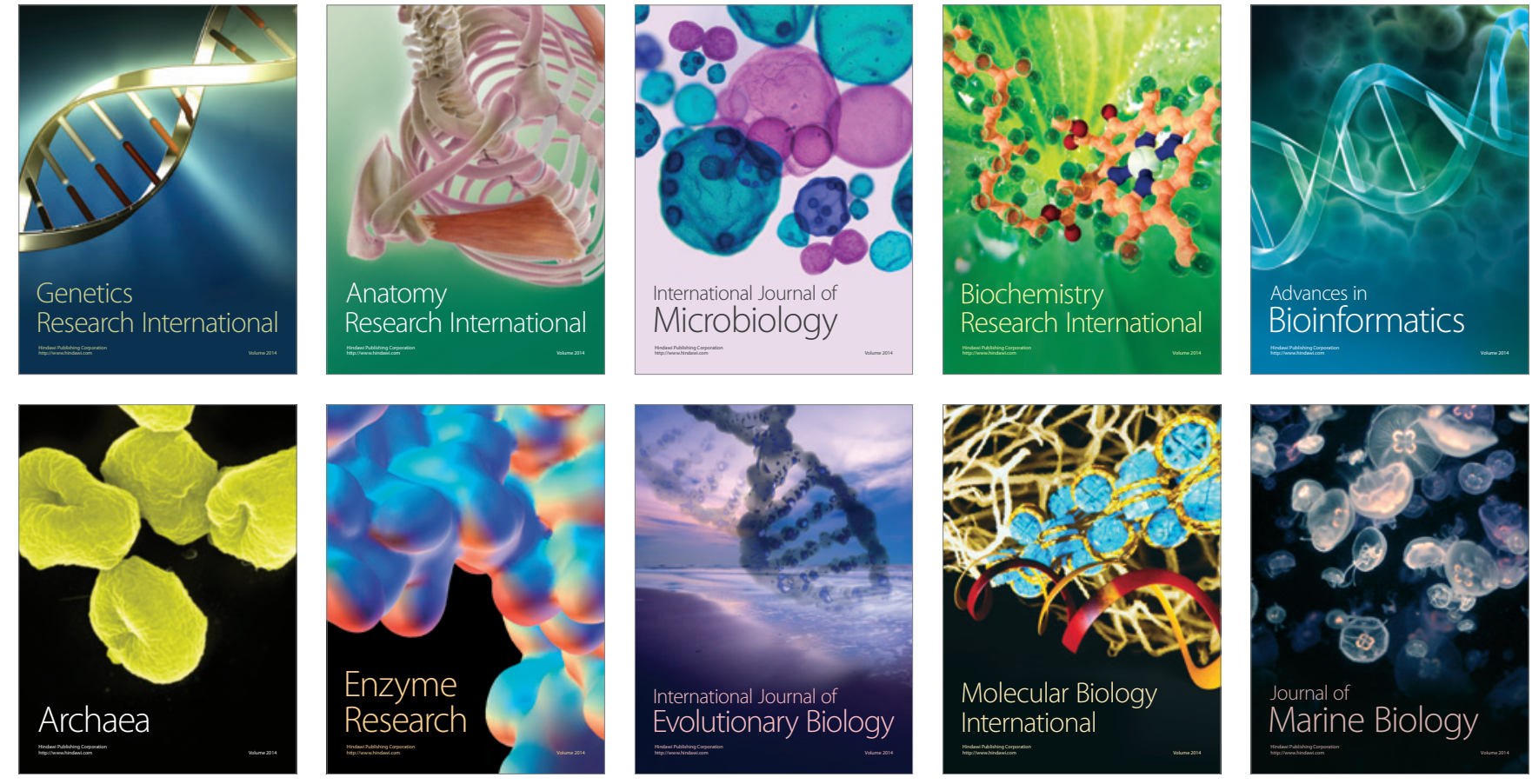